\title{
Phase II trial of docetaxel, cisplatin and fluorouracil followed by carboplatin and radiotherapy in locally advanced oesophageal
}

\section{cancer}

\author{
V Chiarion-Sileni", , L Corti ${ }^{2}$, A Ruol $^{3}$, R Innocente ${ }^{4}$, C Boso², P Del Bianco ${ }^{5}$, J Pigozzo', R Mazzarotto², \\ O Tomassi ${ }^{6}$ and E Ancona ${ }^{3}$
}

'Medical Oncology Unit, Istituto Oncologico Veneto, Padova, Italy; ${ }^{2}$ Radiotherapy Unit, Istituto Oncologico Veneto, Padova, Italy; ${ }^{3}$ Third Surgical Clinic, University Hospital, Padova, Italy; ${ }^{4}$ Department of Radiotherapy, CRO Aviano, Italy; ${ }^{5}$ Clinical Trials and Biostatistics Unit, Istituto Oncologico Veneto,

Padova, Italy; ${ }^{6}$ Medical Oncology Unit, General Hospital, Castelfranco Veneto, Italy

This study was performed to assess the efficacy and safety of docetaxel, cisplatin and fluorouracil combination in patients with unresectable locally advanced oesophageal squamous cell carcinoma. Treatment consisted of docetaxel $60 \mathrm{mg} \mathrm{m}^{-2}$, cisplatin $75 \mathrm{mg} \mathrm{m}^{-2}$ on day I and fluorouracil $750 \mathrm{mg} \mathrm{m}^{-2}$ day $^{-1}$ on days $2-5$, repeated every 3 weeks for three cycles, followed by carboplatin $100 \mathrm{mg} \mathrm{m}^{-2}$ week $^{-1}$ for 5 weeks and concurrent radiotherapy (45 Gy in 25 fractions, 5 days week ${ }^{-1}$ ). After radiotherapy, eligible patients either underwent an oesophagectomy or received high dose rate endoluminal brachytherapy (HDR-EBT). Thirty-one out of 37 enrolled patients completed the planned chemotherapy and 30 completed chemoradiation. After completion of chemotherapy, 49\% (95\% Cl: 32.2-66.2) had a clinical response. Twelve patients (32\%) underwent a resection, which was radical in 60\% (postoperative mortality: 0\%). A pathological complete response was documented in four patients (I I\% of enrolled, $30 \%$ of resected). The median survival was 10.8 months $(95 \% \mathrm{Cl}: 8.1-12.4)$, and the 1 - and 2-year survival rates were 35.1 and $18.9 \%$, respectively. Grade 3-4 toxicities were neutropoenia 32\%, anaemia II\%, non-neutropoenic infections I8\%, diarrhoea 6\% and oesophagitis 5\%. Nine patients (24\%) developed a tracheo-oesophageal fistula during treatment. Even if the addition of docetaxel to cisplatin and 5-fluorouracil (5-FU) seems to be more active than the cisplatin and 5-FU combination, an incremental improvement in survival is not seen, and the toxicity observed in this study population is of concern. In order to improve the prognosis of these patients, new drugs, combinations and strategies with a better therapeutic index need to be identified.

British Journal of Cancer (2007) 96, 432-438. doi: I0.1038/sj.bjc.6603585 www.bjcancer.com

Published online 23 January 2007

(C) 2007 Cancer Research UK

Keywords: chemoradiotherapy; docetaxel; oesophageal cancer; phase II study

Oesophageal cancer is the sixth leading cause of death from cancer worldwide (Pisani et al, 1999) and its fatality rate at 5 years reaches $90 \%$ (Blot and McLaughlin, 1999). The prognosis remains dismal because, at diagnosis, surgery is inappropriate in $40-60 \%$ of patients owing to unresectable primary disease, distant metastases or high operative risk (Sagar et al, 1994).

Of those undergoing operation, between 55 and $80 \%$ will have a 'potentially' curative resection (Muller et al, 1990; Sagar et al, 1994), which is safe only in experienced hands (Siewert et al, 2001).

With radiotherapy alone these results did not improve, and 5 -year survival rates remain $<10 \%$ (al-Sarraf et al, 1997). Chemotherapy can provide significant palliation of symptoms for patients with unresectable, locally advanced or metastatic disease. The repertoire of chemotherapeutic agents with activity against

*Correspondence: Dr V Chiarion-Sileni, Medical Oncology Unit, Istituto Oncologico Veneto, Via Gattamelata 64, 35 I 28 Padova, Italy; E-mail: mgaliz@tiscali.it

Received 14 August 2006; revised 13 December 2006; accepted 13 December 2006; published online 23 January 2007 squamous cell carcinoma (SCC) is restricted, but responses have been documented in studies utilising cisplatin, 5-fluorouracil (5$\mathrm{FU}$ ), vindesine, mytomicin, paclitaxel and vinorelbine (Enzinger et al, 1999). In the multi-modality treatment of oesophageal cancer, cisplatin and continuous-infusion 5-FU (PF), alone or combined with radiotherapy, is the most frequently used regimen (Cooper et al, 1999).

The response rate reported with PF ranged from 35 to $40 \%$ (De Besi et al, 1986; Bleiberg et al, 1997; Ancona et al, 2001), whereas the 2-year survival rates of patients with locally advanced oesophageal cancer ranged from 8 to $55 \%$, with a mean $27 \%$. A better prognosis with chemoradiotherapy/chemotherapy (al-Sarraf et al, 1997; Stuschke et al, 2000; Kodaira et al, 2003; Polee et al, 2003) has been reported, but these series also included patients with potentially resectable carcinomas.

The majority of studies on combined therapy showed longer survival for patients achieving a pathologic complete response (pCR), which can be obtained in $12-40 \%$ of patients treated with PF combined therapy (Forastiere et al, 1997; Ancona et al, 2001). Patients with a less advanced stage are more likely to achieve a pCR than those with a more advanced disease (Rohatgi et al, 2005). 
Therefore, there is a need to test new combinations, specifically in unresectable locally advanced oesophageal patients, with the aim of increasing the pCR rate and survival.

The mechanism of action of docetaxel is different from that of $\mathrm{PF}$ and has proved to have an additive effect with cisplatin and supra-additive antitumour activity with fluorouracil in vitro and in murine models of xeno-grafted human tumours (Burris et al, 1992; Catimel et al, 1994; Dreyfuss et al, 1996). Docetaxel has been shown to be more active than paclitaxel in 10 oesophageal cancer cell lines (Kawamura et al, 1997) and clinically active in patients with oesophageal adenocarcinoma (Einzig et al, 1996). Furthermore, its combination with cisplatin, fluorouracil and leucovorin showed an overall response (OR) of $94 \%$ and a complete response (CR) of $44 \%$ in patients with SCC of the head and neck, without altering the ability to administer definitive radiotherapy (Colevas et al, 1998).

It seemed therefore appropriate to evaluate, in a phase II study, the combination of docetaxel, cisplatin and fluorouracil (DCF) in patients with locally advanced oesophageal SCC.

Italian patients with oesophageal SCC are heavy smokers and drinkers, and often present vascular and peripheral nerve impairment from this abuse. Therefore, we chose to use carboplatin instead of cisplatin during radiotherapy, as continuous carboplatin infusion during radiotherapy has been shown to be cytotoxic as cisplatin in human lung cancer cell lines (Groen et al, 1995a), and active, while less nephro- and neurotoxic, in nonsmall-cell lung and head and neck cancer patients (Groen et al, 1995b; Loreggian et al, 1997).

The study reported here is a prospective phase II trial of DCF, followed by external beam radiotherapy concurrent with continuous carboplatin infusion, designed to evaluate the activity of DCF in patients with locally advanced oesophageal SCC.

Secondary objectives were safety of the combination, the pCR rate in operable patients, local and systemic recurrence and median and overall survival.

\section{PATIENTS AND METHODS}

\section{Eligibility and pretreatment evaluation}

Before entry into the study, all patients were evaluated by a multidisciplinary team, which included a medical oncologist, a radiation therapist, a surgeon and a gastroenterologist. Eligibility criteria were age $<75$ years, histologically proven and previously untreated SCC of the oesophagus, WHO performance status (PS) $\leqslant 2$, absolute neutrophil count $\geqslant 2 \times 10^{9} 1^{-1}$, platelet count $\geqslant 100 \times 10^{9} 1^{-1}$, and adequate renal and hepatic function. Exclusion criteria were evidence of distant metastases, pleural or pericardial effusion, fistulisation, prior malignancies (other than basal cell skin carcinoma), prior myocardial infarction or uncontrolled infections. All patients were required to give written informed consent before entering the study, which was approved by the Ethics Committee of the two participating centres.

Pretreatment evaluation included a medical history, physical examination (PE), complete blood cell count and serum chemistry tests; barium oesophagram; oesophagoscopy; bronchoscopy; endoscopic ultrasound (EUS); computed tomography (CT) scans of the chest and abdomen; cervical US with fine-needle aspiration biopsy of suspicious nodes.

Based on the results of the EUS, patients were assigned a preoperative clinical stage according to the 1997 TNM classification of the International Union Against Cancer (Sobin, 1997). In case of a discrepancy between the CT and EUS findings, we classified the patient according to the worst stage. Only those patients with $\mathrm{T} 3-4$ or N1 or M1 (nodal) disease, unresectable for tracheobronchial infiltration, or an M1a nodal extension, or laryngeal nerve palsy were eligible for this study. One patient with a T2 N1 tumour was also considered eligible owing to the cervical location.

\section{Treatment plan}

Treatment consisted of docetaxel $60 \mathrm{mg} \mathrm{m}^{-2}$, as a 1-h infusion, with $500 \mathrm{ml}$ normal saline on day 1 of a 21-day cycle. Cisplatin $75 \mathrm{mg} \mathrm{m}^{-2}$ was given $1 \mathrm{~h}$ after the completion of docetaxel over $30 \mathrm{~min}$ with a 21 fluid pre-hydration $(0.9 \%$ saline $+30 \mathrm{ml}$ of $10 \%$ $\mathrm{KCl}+12 \mathrm{ml}$ of $10 \% \mathrm{MgCl}_{2}$ ), followed by a 1.51 fluid post-hydration $\left(0.9 \%\right.$ saline $+30 \mathrm{ml}$ of $10 \% \mathrm{KCl}+12 \mathrm{ml}$ of $\left.10 \% \mathrm{MgCl}_{2}\right)$. Fluorouracil $750 \mathrm{mg} \mathrm{m}^{-2}$ day $^{-1}$ was given by intravenous (i.v.) continuous infusion on days $2-5$.

Blood products, nutritional support and all other means of symptomatic relief were allowed according to each patient's needs. Granulocyte colony-stimulating factor, $300 \mu \mathrm{g} \mathrm{day}^{-1}$ subcutaneously, was allowed only in case of neutropoenic fever.

Dose modifications were planned as follows: for haematological toxicity consisting of absolute neutrophil count (ANC) less than 1500 cells $\mathrm{mm}^{-3}$ or platelet count less than 100000 cells $\mathrm{mm}^{-3}$ on day 1, delay of DCF for 1 week; reduction of the dose of all drugs to level $-1(-25 \%)$ for ANC $<500$ cells $\mathrm{mm}^{-3}$, without fever, or platelet count $<50000$ cells $\mathrm{mm}^{-3}$ without bleeding, or grade 3 mucositis according to the National Cancer Institute common toxicity criteria (NCI-CTC, version 2.0 ), and to level $-2(-40 \%)$ for ANC $<500$ cells $\mathrm{mm}^{-3}$ with fever, or platelet count $<50000$ cells $\mathrm{mm}^{-3}$, with bleeding, or grade 4 mucositis; reduction of cisplatin to level -1 for grade 2 renal toxicity and reduction to level -2 for grade 3 renal toxicity.

Interval assessments during the treatment included PE, nutrition evaluation, weekly complete blood cell count with differential and platelet count, and renal and liver function tests every 3 weeks.

Radiation therapy was administered with a high-energy linear accelerator at $6-20 \mathrm{mV}$. The treatment volume included the area of the primary tumour and potential sites of lymphatic involvement. The planned target volume for carcinoma of the upper or middle third oesophagus included the primary tumour with a $5-\mathrm{cm}$ longitudinal margin, metastatic nodes with a $2-\mathrm{cm}$ margin, supraclavicular fossa and mediastinum. For carcinoma of the lower third oesophagus, the field was extended to include both the peri-gastric and celiac nodes. The dose was prescribed to the isodose line, which covered the volume at risk. A daily dose of $1.8 \mathrm{~Gy}$ was given up to a dose of $30.6 \mathrm{~Gy}$. The radiation portals were then changed to encompass the primary tumour and metastatic nodes with a $2-\mathrm{cm}$ margin lesion up to a final dose of $45 \mathrm{~Gy}$. The radiation dose to the spinal cord was maintained at a maximum of $45 \mathrm{~Gy}$.

Carboplatin, $100 \mathrm{mg} \mathrm{m}^{-2}$ week $^{-1}$ i.v. continuous infusion, was concurrently administered with radiotherapy for 5 weeks by an elastomeric infusion pump through a central venous access catheter. Radiation therapy and carboplatin were withheld only if the ANC was $<500$ or the platelet count $<25000$.

Patients who were unable to maintain their weight were started on enteral or parenteral feeding. Patients were withdrawn from the study if they presented progressive disease, life-threatening toxicities, fistulisation or expressed their desire to withdraw.

\section{Surgery, brachytherapy and staging criteria}

Toxicity was graded using the NCI-CTC version 2.0. All events that occurred during the treatment or worsened in comparison with baseline scores were considered toxic.

Patients were restaged 4 weeks after the third DCF cycle and 4-6 weeks after completion of chemoradiation, repeating the pretreatment staging work-up. Clinical CR was defined as a complete symptomatic, radiographic and endoscopic normalisation.

Definition of a clinical partial response (PR) was more difficult; we defined PR as a reduction from the initial clinical stage (AJCC, 
1997) (Fleming, 1997), determined by a compilation of results from the CT scans, EUS, barium oesophagram and endoscopy.

Stable disease (SD) was defined as no change in the TNM stage, and progressive disease (PD) as an increase in the TNM stage or by the discovery of new metastatic lesions at any time. Patterns of failure were defined as the first site of failure. Local failure included the primary tumour and local/regional lymph nodes. Distant failure included any other site of disease recurrence. Dysphagia was scored before the treatment and at each subsequent PE, using a published dysphagia scale (Knyrim et al, 1993): a score of 0 denoted no dysphagia; 1 , trouble in swallowing solids; 2 , the ability to swallow semi-solids alone; 3 , the ability to swallow liquids alone; and 4, complete dysphagia to solids and liquids.

Patients who obtained a CR or a PR were offered an Ivor-Lewis oesophagectomy. Resection and reconstruction were accomplished using simultaneous right thoracotomy and midline laparotomy. For cervical and upper thoracic lesions, a concomitant pharyngolaryngectomy was carried out together with a three-field lymphadenectomy. Pathological complete remission (pCR) was defined as the absence of residual tumour in the resected oesophageal and nodal specimen ( $\mathrm{pTON} 0$ ). Patients who refused or were considered unfit for surgery were offered a high dose rate endoluminal brachytherapy (HDR-EBT) boost with the aim of improving local control. High dose rate endoluminal brachytherapy was performed once weekly for 3 consecutive weeks and started 2-4 weeks after chemotherapy and radiotherapy completion, to allow resolution qof oesophageal mucositis. A radio-opaque clip was placed on the oesophageal mucosa, $1 \mathrm{~cm}$ above the tumour bed, via endoscopy. This device substantially facilitates the radiological localisation of the tumour bed when positioning the applicator charged with a dummy source. The mean total dose was $15 \mathrm{~Gy}, 5 \mathrm{~Gy}$ per session, prescribed at $0.6 \mathrm{~cm}$ from the surface of a flexible applicator with a diameter of $0.8 \mathrm{~cm}$. The active length, planned at the time of endoscopy, was the visible mucosal tumour with a $2 \mathrm{~cm}$ distal and proximal margin, without optimisation.

\section{Statistical methods}

The primary outcome of this study was the OR rate, defined as the proportion of responders (complete or partial) among all patients, of the DCF combination in locally advanced oesophageal SCC patients. The sample size was calculated based on the assumption that a $40 \%$ OR rate or less was considered insufficient to warrant further investigation. On the other hand, a probability of response above $60 \%$ would be clinically sufficient and indicates that further investigation of this regimen is appropriate. The accrual consisted of two stages according to Simon (1989).

This design minimises the expected number of treated patients, if the response rate is inadequate. If seven or less responses were observed in the first 19 patients, the study would have been terminated. In the case of eight or more responses in these 19 patients, 15 additional patients would have been enrolled. If more than 16 responses were observed among all of the 34 patients, the treatment would be considered active. This scheme ensured that the chance of erroneously rejecting the treatment is less than $10 \%$ if the treatment is active in at least $60 \%$ of the patients, whereas the probability of erroneously recommending a treatment whose response rate is inadequate is limited to $15 \%$. Confidence intervals were adjusted for the two-stage design (Atkinson and Brown, 1985). Secondary end points were the pathological remission rate, the toxicity rate, dysphagia response and survival times.

Survival times were calculated from the beginning of chemotherapy to the date of death, progressive disease or to last followup. The Kaplan-Meier method was used to estimate the survival curves.

Actual dose intensity was calculated as recommended by Hryniuk and Goodyear (1990).
Analyses were performed using the SAS statistical package (SAS, release 8.02 , Cary, NC, USA)

\section{RESULTS}

\section{Patient characteristics}

Between July 1998 and February 2002, 37 patients were enrolled in the study at two Italian oncology centres: the Medical Oncology Unit of the Istituto Oncologico Veneto, Padova and the Centro di Riferimento Oncologico, Aviano. Characteristics of the 37 patients are listed in Table 1 . The median age was 61 years (range, $39-72$ years), and $62 \%$ of patients had a WHO PS of 2 .

Twenty-six patients had T4 disease, 31 had mediastinal, two coeliac and three cervical node metastases; one patient had unsuspected bone metastasis. Twenty-five primary tumours were in the upper-mid-thoracic oesophagus, four in the cervical, two in the lower thoracic and six patients had more than one location. All patients had dysphagia before treatment: four (11\%) grade $1 ; 16$ $(43 \%)$ grade $2 ; 11(30 \%)$ grade 3 ; six (16\%) grade 4 and almost $50 \%$ of patients had suffered a weight loss $\geqslant 10 \%$. According to Simon's design, 19 patients entered the first stage of study . Fifteen patients were required for the second stage. As it was expected that some patients might not be fully evaluable, 37 patients were finally recruited.

\section{Response and dysphagia relief}

Response results are summarised in Table 2. Among the first 19 patients, 10 responses were observed. The OR rate, on an intention-to-treat analysis, was $48.6 \%$ (18 of 37 patients) $(95 \%$ adjusted CI: 32.2 - 66.2\%). Six patients (16\%) had a CR with negative biopsies, $12(32 \%)$ obtained a PR, seven patients (19\%) remained stable, eight (22\%) had PD and four (11\%) early death. After carboplatin infusion and radiotherapy, two patients had a further reduction of disease, 20 remained stable and eight had progressive disease. All patients reported some grade of dysphagia on trial entry. Median baseline score was 2 (range 1-4). After induction chemotherapy, dysphagia improved by at least one level in eight patients (22\%) and completely resolved in 12 patients $(32 \%)$, with an overall improvement in dysphagia in $54 \%$ of

Table I Patient characteristics

\begin{tabular}{lcc}
\hline Characteristics & No. of patients & $\%$ \\
\hline Total & 37 & \\
Age (years) & & \\
$\quad$ Median (range) & $61(39-72)$ & 78 \\
Gender & 29 & 22 \\
$\quad$ Male & 8 & 38 \\
Female & 14 & 62 \\
ECOG performance status & 23 & 3 \\
I & & 13 \\
2 & 1 & 70 \\
Clinical stage & 5 & 14 \\
T2 NI & $26^{\mathrm{b}}$ & 11 \\
T3 NI & 5 & 68 \\
T4 N0-1 & & 5 \\
T3-4 N0- I Mla & 4 & 16 \\
Tumour location & 25 & 49 \\
Cervical & 2 & \\
Upper-middle & 6 & \\
Lower & 18 & \\
More than one site & & \\
Weight loss > 10\% & & \\
\hline
\end{tabular}

${ }^{\mathrm{a}} \mathrm{ECOG}=$ Eastern Cooperative Oncology Group. ${ }^{\mathrm{b}}$ One of these patients had bone metastases. 
patients. Dysphagia worsened in eight (22\%) and six required placement of an enteral feeding tube for nutritional support. Nine (24\%) developed a tracheo-oesophageal fistula, four during induction therapy and five during or at the end of radiotherapy.

\section{Surgery and brachytherapy}

Of the 12 patients who underwent surgery, seven (58\%) had a complete surgical resection with clear margins, two had a macroscopic clearance but positive resection margins on histological assessment, three had a macroscopically incomplete resection owing to tumour adherence to the trachea in two and to the aorta wall in one. There were no postoperative deaths and a pCR was documented in four patients $(30 \%$ of resected and $10.8 \%$ of enrolled, respectively).

All the seven patients treated with HDR-EBT recurred locally.

\section{Toxicity and treatment delivery}

Toxicity data are available for all patients. The most frequently encountered toxicities were leucopoenia ( $38 \%$ grade III/IV), neutropoenia ( $32 \%$ grade III/IV), anaemia ( $11 \%$ grade III/IV), mucositis (35\% grade II and $5 \%$ grade III), non-neutropoenic infections ( $13 \%$ grade III/IV) and diarrhoea (6\% grade III/IV) (Table 3). All patients experienced grade II alopecia. One patient died of a cerebral stroke ( $3 \%$ grade IV). Among the nonneutropoenic infections, we observed two, non-fatal, mycotic pneumonitis. Two fatal mediastinitis, due to a fistulisation, occurred immediately after the first cycle. One patient died after the third cycle owing to a neutropoenic fever and diarrhoea.

The cycles delivered were 103 over 111 planned; delays in chemotherapy owing to toxicity were required in three patients, with a maximum delay of 14 days. No dose reductions were made.

The planned dose intensity was $20 \mathrm{mg} \mathrm{m}^{-2}$ week $^{-1}$ for docetaxel, $25 \mathrm{mg} \mathrm{m}^{-2}$ week $^{-1}$ for cisplatin and $750 \mathrm{mg} \mathrm{m}^{-2}$ week $^{-1}$ for fluorouracil.

The median percentage of dose intensity delivered was $96 \%$ for docetaxel, $98 \%$ for cisplatin and $98 \%$ for fluorouracil (Table 4).

Table 2 Response rate to chemotherapy

\begin{tabular}{lccc}
\hline & \multicolumn{3}{c}{ DCF $^{\mathbf{a}}$ response } \\
\cline { 2 - 4 } Responses & No. of patients & $\%$ & $\mathbf{9 5 \%} \mathbf{~ C l}$ \\
\hline Overall response & 18 & 49 & $32-66$ \\
$\quad$ Complete response & 6 & & \\
Partial response & 12 & 19 & \\
Stable disease & 7 & 22 & \\
Progressive disease & 8 & 11 & \\
Early death & 4 & &
\end{tabular}

${ }^{\mathrm{a} D}$ Docetaxel, cisplatin and fluorouracil. $\mathrm{Cl}=$ confidence interval.
The main toxicity during chemoradiotherapy was grade III and IV oesophagitis in $73 \%$ of patients. All patients received the planned weekly dose of carboplatin without delay and/or evidence of haematological toxicity. Thirty patients received the carboplatine-radiotherapy segment with a mean total radiation dose of $45 \mathrm{~Gy}$ (range 30-60 Gy). One patient stopped XRT after $30 \mathrm{~Gy}$ owing to the occurrence of a tracheo-oesophageal fistula and two patients continued to $60 \mathrm{~Gy}$ because they were unfit for surgery.

After carboplatin and radiotherapy, 18 downstaged patients were referred to the surgeon: 12 were operated, one refused and the remaining five were considered medically unfit for surgical resection. These six patients and one with a cervical tumour location were treated with HDR-EBT.

Two patients died of a myocardial failure 225 and 479 days from the start of therapy, one of them without evidence of disease.

\section{Survival and pattern of failure}

The median survival was 10.8 months (95\% CI: $8.1-12.4)$, and 1 - and 2-year survival rates were $35.1 \%$ (95\% CI: $20.4-50.2$ ) and 18.9\% (95\% CI: 8.3-32.8) (Figure 1). Currently, of 37 DCF-treated patients, four $(11 \%)$ are alive and disease-free, with a minimum follow-up of 50 months. Fifteen out of the 18 responding patients progressed or relapsed. The median time to progression was 9.8 months (95\% CI: 8.5 - 16.0) and 1- and 2-year progression-free survival rates were $38.9 \%$ (95\% CI: $17.5-60.0$ ) and $22.2 \%$ (95\% CI: 6.9 - 42.9), respectively (Figure 2). The median survival of DCF responding patients was 14.7 months (95\% CI: 11 - 24.7) vs 6.6 months (95\% CI: $3.9-9.8$ ) of non-responding.

Thirty patients are evaluable for progression site: 10 patients (33.3\%) had a local progression, four $(13.3 \%)$ had distant metastases without local recurrence and 16 (53.3\%) had both.

Table 3 Docetaxel, cisplatin and fluorouracil chemotherapy toxicity

\begin{tabular}{lcccc}
\hline & \multicolumn{4}{c}{ Common toxicity criteria (\%) $(\mathbf{n o .}=\mathbf{3 7})$} \\
\cline { 2 - 5 } Toxicities & Grade I & Grade 2 & Grade $\mathbf{3}$ & Grade 4 \\
\hline Leucopoenia & 39 & 19 & 27 & 11 \\
Neutropoenia & 29 & 19 & 24 & $8^{\mathrm{a}}$ \\
Thrombocytopoenia & 8 & 8 & 5 & 0 \\
Anaemia & 46 & 22 & 8 & 3 \\
Mucositis & 27 & 35 & 5 & 0 \\
Alopecia & 0 & 100 & 0 & 0 \\
Nausea and vomiting & 19 & 13 & 3 & 0 \\
Diarrhoea & 0 & 0 & 3 & 3 \\
Hepatic & 3 & 0 & 0 & 0 \\
Infection & 0 & 0 & 3 & 8 \\
Cerebrovascular & 0 & 0 & 0 & $3^{\mathrm{a}}$ \\
Fistula & 0 & 0 & 0 & $11^{\mathrm{a}}$ \\
\hline
\end{tabular}

${ }^{\text {a }}$ Toxic deaths occurred in four patients.

Table 4

Dose of docetaxel, cisplatin and fluorouracil and actual dose intensity

\begin{tabular}{|c|c|c|c|}
\hline & Docetaxel & Cisplatin & Fluorouracil \\
\hline & Median (range) & Median (range) & Median (range) \\
\hline
\end{tabular}

${ }^{\mathrm{a}} \mathrm{DI}=$ dose intensity. 


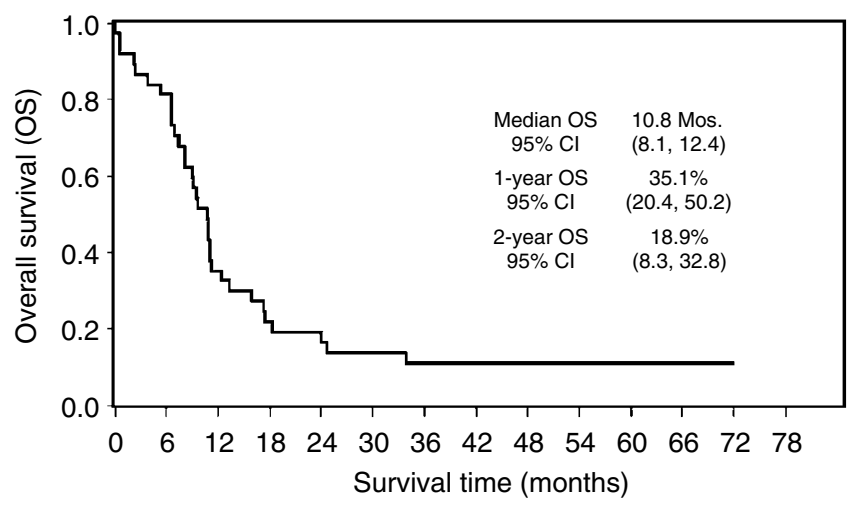

$\begin{array}{llllllllllllll}\text { At risk } & 37 & 30 & 13 & 8 & 7 & 5 & 4 & 4 & 4 & 3 & 2 & 2 & 1\end{array}$

Figure I Overall survival for all patients. Survival time was calculated from the start of chemotherapy to the date of death or to the last follow-up.

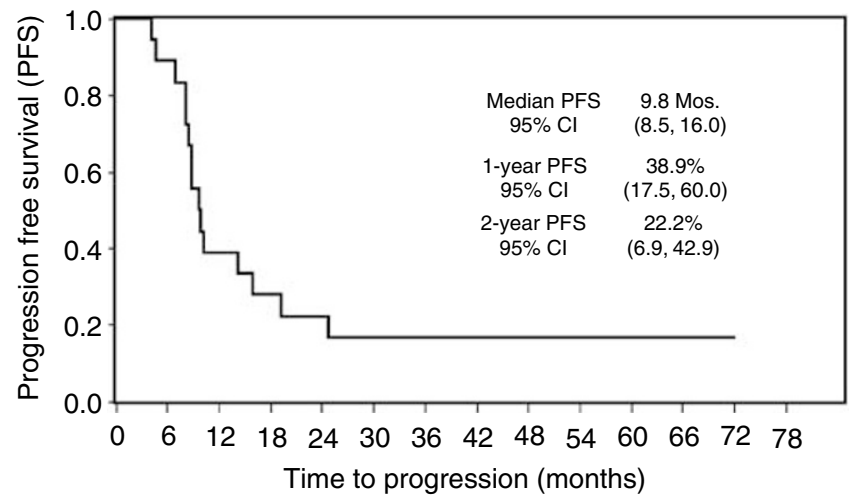

$\begin{array}{llllllllllllll}\text { At risk } & 18 & 16 & 8 & 5 & 4 & 3 & 3 & 3 & 3 & 2 & 1 & 1 & 1\end{array}$

Figure 2 Progression-free survival for responding patients. Time to progression was calculated from the start of chemotherapy to the date of progression or to the last follow-up.

The most frequent sites of distant metastases were lungs (11 patients), bone (five), cutis and subcutis (three).

\section{DISCUSSION}

In this population of locally advanced oesophageal SCC patients, DCF showed substantial activity in the treatment of oesophageal cancer. The $49 \%$ response rate observed is higher than that reported with cisplatin and 5-FU alone (De Besi et al, 1986; Bleiberg et al, 1997), which is still considered the standard treatment.

In the last decade, several attempts have been made to test new agents, especially taxanes, topoisomerase I inhibitors and vinorelbine. However, differences in the study population make the comparison difficult, as some studies had included both locally advanced tumours and metastatic disease, or metastatic disease alone, and others had included both adenocarcinoma and SCC. Despite a similar chemosensitivity reported for adenocarcinoma and SCC (Ilson et al, 1997), the adenocarcinoma tumour type was an independent prognostic parameter in a large Western world series (Siewert et al, 2001).

Paclitaxel used alone at different doses or combined with cisplatin gave an RR of 14.5-50\% (Ajani et al, 1994; Kelsen et al,
1997; Petrasch et al, 1998) with a treatment-related mortality of $10 \%$ and hospitalisation owing to toxicity in $50 \%$ of the patients.

Irinotecan was evaluated in combination with cisplatin in a weekly schedule, reporting 20 responses in 35 patients $(57 \%)$ in the first publication, although in a subsequent publication from the same author, only 10 (36\%) confirmed major responses were reported (Ilson et al, 1999; Ilson, 2004).

Irinotecan was also combined with docetaxel, obtaining an RR of $30 \%$, in metastatic patients, with an extremely high incidence of febrile neutropoenia (43\%) (Govindan et al, 2003).

The combination of vinorelbine and cisplatin was tested only in metastatic patients, obtaining an RR of $34 \%$ with acceptable toxicity (Conroy et al, 2002).

Docetaxel alone was tested in 52 metastatic patients, obtaining an RR of $20 \%$ with a median survival time of 8.1 months; febrile neutropoenia was the main toxicity and was observed in $18 \%$ of the patients (Muro et al, 2004). Docetaxel was also investigated in combination with cisplatin, obtaining four responses out of 10 patients with metastatic SCC (Laack et al, 2005) and in combination with capecitabine, obtaining 11 responses out of 24 patients with metastatic disease (Lorenzen et al, 2005).

The combination of docetaxel, cisplatin and 5-FU, evaluated in recurrent and previously treated patients, achieved major responses in four out of 10 patients; however, a grade 3/4 leukopoenia occurred in eight of them (Tanaka et al, 2003).

Our study is the first to test this combination in a homogenous population of previously untreated squamous oesophageal carcinoma patients, even if characterised by poor prognostic characteristics: $62 \%$ of patients had a grade 2 WHO PS, $84 \%$ had nodal involvement, $14 \%$ had non-regional lymph node metastases (M1a) and $89 \%$ had a primary lesion located above the carina. The median survival expected with palliative treatment as radiotherapy or intubation with self-expanding stents in these patients is only 3-6 months (Knyrim et al, 1993). The RR of $49 \%$ and the median survival of 10.8 months, with an improvement of dysphagia in more than $50 \%$ of patients, and a 1- and 2-year survival of 35 and $19 \%$, clearly suggest that DCF combination is active, that chemoradiotherapy is the best palliation for patients with inoperable locally advanced oesophageal SCC and that this approach might be curative in some.

The treatment of these patients presents significant clinical problems related not only to the extension and location of disease, but also to their poor clinical and nutritional status owing to the long use of tobacco and alcohol, and made worse by the feeding impairment, resulting in an increase in complications, as well as toxic and early deaths. These complications are more frequent in SCC than in adenocarcinoma patients, as observed by others (Adelstein et al, 2000). In our study, the early deaths, partly related to disease complications and partly related to treatment toxicity, were $10.8 \%$. This clearly disappointing percentage is inferior to the $18 \%$ reported by Adelstein et al (2000) with a paclitaxel combination, and has been previously reported in oesophageal cancer, even in patients with a less advanced stage of disease (Bleiberg et al, 1997; Wright et al, 1997). We observed that only patients with a WHO PS of 2 developed fatal toxicity; therefore, careful patient selection, improvement in liquid and nutritive intake, as well as the prophylactic use of antibiotics could be beneficial and recommendable before starting therapy. The high percentage of fistulisation observed might be explained by the prevalence of T4 lesions, localised mostly in the upper or middle portion of the oesophagus. The high risk of treatment-related perforation of the oesophageal wall in T4 oesophageal patients was also highlighted by Ohtsu et al (1999). In order to reduce the perforation risk, we decided to use induction chemotherapy, before chemoradiotherapy, with the hope of decreasing the tumour volume before encountering severe oesophagitis and stomatitis. Unfortunately, this strategy seemed to be ineffective, even if the dysphagia improved in the majority of patients. 
The placement of a self-expanding feeding tube might have been more effective in preventing this complication; however, it was inapplicable in some patients owing to the extension or the location of the lesion, was not accepted by others and, moreover, might have interfered with the subsequent response evaluation. A change in the chemotherapy schedule, like the use of weekly doses, might help to reduce the acute tumour necrosis and permit wall repair (Ilson et al, 2003).

In this study, only five patients had M1 disease, making a comparison between them and other patients inadequate. However, it should be pointed out that three of them responded to the treatment, one obtained a pCR and another is one of the four long living. These findings are similar to the results reported by Ohtsu et al (1999)) and Polee et al (2003)) and support the concept that chemoradiotherapy has the same curative potential, for locally advanced disease, irrespective of mediastinal or M1a node extension; therefore, separating these groups is not strictly necessary. The utility of surgical resection after chemoradiotherapy in advanced oesophageal cancer is still not established; in spite of this, we offered responding patients the possibility of resection, as this was the best way to ascertain the rate of complete response, and residual tumour resection could be beneficial. Currently, only radically resected patients are long survivors in our study, despite evidence of residual tumour in three of them.

This result, together with that of others, seems to imply that surgical resection could be useful at least in some patients (Adelstein et al, 2000; Ilson et al, 2003). No conclusions can be drawn on the utility of HDR-EBT in the local control of disease from our data, as few patients received this treatment. We can, however, say that the planned dose of $15 \mathrm{~Gy}$ in three fractions was well tolerated with minimal acute effects, even if all patients progressed. Local recurrences (87\%), all within the radiation field, remain the most important cause of death. We can argue that the dilation of radiotherapy and its combination with carboplatin alone could have hampered the adequate local control of the disease. Nevertheless, a similar rate $(77 \%)$ of local failure was reported by Ohtsu et al (1999) who delivered a total dose of $60 \mathrm{~Gy}$ concomitant with PF, followed by two more courses of PF alone. Thus, this high rate of local recurrences is more likely related to the advanced stage of the disease than to the dilation of radiotherapy, or to the dose and schedule used.

Our results suggest that DCF is an active regimen with curative potential in some patients with unresectable locally advanced oesophageal SCC. However, survival is still disappointing and not improved over standard cisplatin/5-FU regimens. The toxicity observed in treating these patients is still relevant and in someway might hamper the clinical efficacy. In order to improve the prognosis of these patients, new drugs, combinations and strategies with a better therapeutic index need to be identified.

\section{ACKNOWLEDGEMENTS}

We thank Denise Kilmartin for editing the manuscript.

\section{REFERENCES}

Adelstein DJ, Rice TW, Rybicki LA, Larto MA, Ciezki J, Saxton J, DeCamp M, Vargo JJ, Dumot JA, Zuccaro G (2000) Does paclitaxel improve the chemoradiotherapy of locoregionally advanced esophageal cancer? A nonrandomized comparison with fluorouracil-based therapy. J Clin Oncol 18: 2032-2039

Ajani JA, Ilson DH, Daugherty K, Pazdur R, Lynch PM, Kelsen DP (1994) Activity of taxol in patients with squamous cell carcinoma and adenocarcinoma of the esophagus. J Natl Cancer Inst 86: 1086-1091

al-Sarraf M, Martz K, Herskovic A, Leichman L, Brindle JS, Vaitkevicius VK, Cooper J, Byhardt R, Davis L, Emami B (1997) Progress report of combined chemoradiotherapy versus radiotherapy alone in patients with esophageal cancer: an intergroup study. J Clin Oncol 15: 277-284

Ancona E, Ruol A, Santi S, Merigliano S, Sileni VC, Koussis H, Zaninotto G, Bonavina L, Peracchia A (2001) Only pathologic complete response to neoadjuvant chemotherapy improves significantly the long term survival of patients with resectable esophageal squamous cell carcinoma: final report of a randomized, controlled trial of preoperative chemotherapy versus surgery alone. Cancer 91: 2165-2174

Atkinson EN, Brown BW (1985) Confidence limits for probability of response in multistage phase II clinical trials. Biometrics 41: 741-744

Bleiberg H, Conroy T, Paillot B, Lacave AJ, Blijham G, Jacob JH, Bedenne L, Namer M, De Besi P, Gay F, Collette L, Sahmoud T (1997) Randomised phase II study of cisplatin and 5-fluorouracil (5-FU) versus cisplatin alone in advanced squamous cell oesophageal cancer. Eur J Cancer 33: $1216-1220$

Blot WJ, McLaughlin JK (1999) The changing epidemiology of esophageal cancer. Semin Oncol 26: 2-8

Burris H, Irvin R, Kuhn J, Kalter S, Smith L, Shaffer D, Rodriguez G, Weiss G, Eckardt J, Vreeland F, Baysass M, Von Hoff D (1992) A phase I clinical trial of taxotere as a $6 \mathrm{~h}$ infusion repeated every 21 days in patients with refractory solid tumors [abstract]. Proc Am Soc Clin Oncol 11: 137

Catimel G, Verweij J, Mattijssen V, Hanauske A, Piccart M, Wanders J, Franklin H, Le Bail N, Clavel M, Kaye SB (1994) Docetaxel (Taxotere): an active drug for the treatment of patients with advanced squamous cell carcinoma of the head and neck. EORTC Early Clinical Trials Group. Ann Oncol 5: 533-537

Colevas AD, Busse PM, Norris CM, Fried M, Tishler RB, Poulin M, Fabian RL, Fitzgerald TJ, Dreyfuss A, Peters ES, Adak S, Costello R, Barton JJ,
Posner MR (1998) Induction chemotherapy with docetaxel, cisplatin, fluorouracil, and leucovorin for squamous cell carcinoma of the head and neck: a phase I/II trial. J Clin Oncol 16: 1331-1339

Conroy T, Etienne PL, Adenis A, Ducreux M, Paillot B, Oliveira J, Seitz JF, Francois E, Van Cutsem E, Wagener DJ, Kohser F, Daamen S, Praet M, Gorlia T, Baron B, Wils J (2002) Vinorelbine and cisplatin in metastatic squamous cell carcinoma of the oesophagus: response, toxicity, quality of life and survival. Ann Oncol 13: 721-729

Cooper JS, Guo MD, Herskovic A, Macdonald JS, Martenson Jr JA, Al-Sarraf M, Byhardt R, Russell AH, Beitler JJ, Spencer S, Asbell SO, Graham MV, Leichman LL (1999) Chemoradiotherapy of locally advanced esophageal cancer: long-term follow-up of a prospective randomized trial (RTOG 8501). Radiation Therapy Oncology Group. JAMA 281: 1623-1627

De Besi P, Sileni VC, Salvagno L, Tremolada C, Cartei G, Fosser V, Paccagnella A, Peracchia A, Fiorentino M (1986) Phase II study of cisplatin, 5-FU, and allopurinol in advanced esophageal cancer. Cancer Treat Rep 70: 909-910

Dreyfuss AI, Clark JR, Norris CM, Rossi RM, Lucarini JW, Busse PM, Poulin MD, Thornhill L, Costello R, Posner MR (1996) Docetaxel: an active drug for squamous cell carcinoma of the head and neck. J Clin Oncol 14: $1672-1678$

Einzig AI, Neuberg D, Remick SC, Karp DD, O’Dwyer PJ, Stewart JA, Benson III AB (1996) Phase II trial of docetaxel (Taxotere) in patients with adenocarcinoma of the upper gastrointestinal tract previously untreated with cytotoxic chemotherapy: the Eastern Cooperative Oncology Group (ECOG) results of protocol E1293. Med Oncol 13: 87-93

Enzinger PC, Ilson DH, Kelsen DP (1999) Chemotherapy in esophageal cancer. Semin Oncol 26: $12-20$

Fleming IE (1997) AJCC Cancer Staging Manual. Philadelphia, PA: Lippincot-Raven.

Forastiere AA, Heitmiller RF, Kleinberg L (1997) Multimodality therapy for esophageal cancer. Chest 112: 195S-200S

Govindan R, Read W, Faust J, Trinkaus K, Ma MK, Baker SD, McLeod HL, Perry MC (2003) Phase II study of docetaxel and irinotecan in metastatic or recurrent esophageal cancer: a preliminary report. Oncology (Williston Park) 17: 27-31

Groen HJ, Sleijfer S, Meijer C, Kampinga HH, Konings AW, De Vries EG, Mulder NH (1995a) Carboplatin- and cisplatin-induced potentiation of 
moderate-dose radiation cytotoxicity in human lung cancer cell lines. $\mathrm{Br}$ J Cancer 72: $1406-1411$

Groen HJ, van der Leest AH, de Vries EG, Uges DR, Szabo BG, Mulder NH (1995b) Continuous carboplatin infusion during 6 weeks' radiotherapy in locally inoperable non-small-cell lung cancer: a phase I and pharmacokinetic study. Br J Cancer 72: $992-997$

Hryniuk WM, Goodyear M (1990) The calculation of received dose intensity. J Clin Oncol 8: 1935-1937

Ilson DH (2004) Phase II trial of weekly irinotecan/cisplatin in advanced esophageal cancer. Oncology (Williston Park) 18: $22-25$

Ilson DH, Bains M, Ginsberg RJ, Kelsen DP (1997) Neoadjuvant therapy of esophageal cancer. Surg Oncol Clin N Am 6: 723-740

Ilson DH, Bains M, Kelsen DP, O'Reilly E, Karpeh M, Coit D, Rusch V, Gonen M, Wilson K, Minsky BD (2003) Phase I trial of escalating-dose irinotecan given weekly with cisplatin and concurrent radiotherapy in locally advanced esophageal cancer. J Clin Oncol 21: 2926-2932

Ilson DH, Saltz L, Enzinger P, Huang Y, Kornblith A, Gollub M, O’Reilly E, Schwartz G, DeGroff J, Gonzalez G, Kelsen DP (1999) Phase II trial of weekly irinotecan plus cisplatin in advanced esophageal cancer. J Clin Oncol 17: $3270-3275$

Kawamura H, Terashima M, Ikeda K, Takiyama I, Sasaki N, Ishiba K, Saito K (1997) Antitumor activities of Taxotere and Taxol against human esophageal cancer [abstract]. Proc Am Assoc Cancer Res 38: 1540

Kelsen D, Ginsberg R, Bains M, Cooper J, Arquette M, Forastiere AA, Ilson D (1997) A phase II trial of paclitaxel and cisplatin in patients with locally advanced metastatic esophageal cancer: a preliminary report. Semin Oncol 24: S19-77-S19-81

Knyrim K, Wagner HJ, Bethge N, Keymling M, Vakil N (1993) A controlled trial of an expansile metal stent for palliation of esophageal obstruction due to inoperable cancer. $N$ Engl J Med 329: 1302 - 1307

Kodaira T, Fuwa N, Itoh Y, Kamata M, Furutani K, Hatooka S, Shinoda M (2003) Multivariate analysis of treatment outcome in patients with esophageal carcinoma treated with definitive radiotherapy. Am J Clin Oncol 26: $392-397$

Laack E, Andritzky B, Durk H, Burkholder I, Edler L, Schuch G, Boeters I, Gorn M, Lipp R, Horst H, Popp J, Hossfeld DK (2005) Docetaxel and cisplatin as first-line treatment for patients with metastatic esophageal cancer: a pilot study. Onkologie 28: 647-650

Loreggian L, Chiarion Sileni V, Fede A, Friso ML, Lora O, Barbara R, Riddi F, Paccagnella A (1997) Chemo-radiotherapy in the elderly and/or poor performance status patients with advanced head and neck cancer. Radiol Oncol 31: 168-170

Lorenzen S, Duyster J, Lersch C, von Delius S, Hennig M, Bredenkamp R, Peschel C, Lordick F (2005) Capecitabine plus docetaxel every 3 weeks in first- and second-line metastatic oesophageal cancer: final results of a phase II trial. Br J Cancer 92: 2129-2133

Muller JM, Erasmi H, Stelzner M, Zieren U, Pichlmaier H (1990) Surgical therapy of oesophageal carcinoma. Br J Surg 77: 845-857
Muro K, Hamaguchi T, Ohtsu A, Boku N, Chin K, Hyodo I, Fujita H, Takiyama W, Ohtsu T (2004) A phase II study of single-agent docetaxel in patients with metastatic esophageal cancer. Ann Oncol 15: 955-959

Ohtsu A, Boku N, Muro K, Chin K, Muto M, Yoshida S, Satake M, Ishikura S, Ogino T, Miyata Y, Seki S, Kaneko K, Nakamura A (1999) Definitive chemoradiotherapy for T4 and/or M1 lymph node squamous cell carcinoma of the esophagus. J Clin Oncol 17: 2915-2921

Petrasch S, Welt A, Reinacher A, Graeven U, Konig M, Schmiegel W (1998) Chemotherapy with cisplatin and paclitaxel in patients with locally advanced, recurrent or metastatic oesophageal cancer. Br J Cancer 78: $511-514$

Pisani P, Parkin DM, Bray F, Ferlay J (1999) Estimates of the worldwide mortality from 25 cancers in 1990. Int J Cancer 83: 18-29

Polee MB, Hop WC, Kok TC, Eskens FA, van der Burg ME, Splinter TA, Siersema PD, Tilanus HW, Stoter G, van der Gaast A (2003) Prognostic factors for survival in patients with advanced oesophageal cancer treated with cisplatin-based combination chemotherapy. Br J Cancer 89: 2045 2050

Rohatgi P, Swisher SG, Correa AM, Wu TT, Liao Z, Komaki R, Walsh GL, Vaporciyan AA, Rice DC, Roth JA, Ajani JA (2005) Characterization of pathologic complete response after preoperative chemoradiotherapy in carcinoma of the esophagus and outcome after pathologic complete response. Cancer 104: 2365-2372

Sagar PM, Gauperaa T, Sue-Ling H, McMahon MJ, Johnston D (1994) An audit of the treatment of cancer of the oesophagus. Gut 35: 941-945

Siewert JR, Stein HJ, Feith M, Bruecher BL, Bartels H, Fink U (2001) Histologic tumor type is an independent prognostic parameter in esophageal cancer: lessons from more than 1,000 consecutive resections at a single center in the Western world. Ann Surg 234: 360-367, discussion 368-369

Simon R (1989) Optimal two-stage designs for phase II clinical trials. Control Clin Trials 10: 1-10

Sobin LH, Wittekind C (1997) International Union Against Cancer (UICC): TNM Classification of Malignant Tumours. New York: John Willey

Stuschke M, Stahl M, Wilke H, Walz M, Oldenburg A, Stuben G, Seeber S, Sack H (2000) Induction chemotherapy followed by concurrent chemotherapy and high-dose radiotherapy for locally advanced squamous cell carcinoma of the upper-thoracic and midthoracic esophagus. Am J Clin Oncol 23: 233-238

Tanaka T, Sueyoshi S, Sasahara H, Matono S, Yamana H, Shirouzu K, Fujita $\mathrm{H}$ (2003) [Preliminary evaluation of chemotherapy with docetaxel, 5-FU, CDDP for recurrent esophageal cancer - a pilot study]. Gan To Kagaku Ryoho 30: 1955-1958

Wright CD, Wain JC, Lynch TJ, Choi NC, Grossbard ML, Carey RW, Moncure AC, Grillo HC, Mathisen DJ (1997) Induction therapy for esophageal cancer with paclitaxel and hyperfractionated radiotherapy: a phase I and II study. J Thorac Cardiovasc Surg 114: 811 -815, discussion 816 